\title{
The Income and Consumption Effects of COVID-19 and the Role of Public Policy*
}

\author{
Suphanit Piyapromdee $\dagger$ and Peter Spittal $\ddagger$
}

\author{
†University College London \\ (s.piyapromdee@ucl.ac.uk) \\ †Uiversity of Bristol \\ (peter.spittal@bristol.ac.uk)
}

\begin{abstract}
We provide empirical evidence on the labour market impacts of COVID-19 in the UK and assess the effectiveness of mitigation policies. We estimate the relationship between employment outcomes and occupational and industrial characteristics and assess the effects on consumption. Seventy per cent of households in the bottom fifth of the earnings distribution hold insufficient assets to maintain current spending for more than one week. We compare the effectiveness of the UK's Coronavirus Job Retention Scheme and of Economic Impact Payments in the US. The EIPs are more effective at mitigating consumption reductions as they have full coverage, depend on household structure and are higher for low-income workers.
\end{abstract}

\section{Introduction}

COVID-19 has created new challenges for public policy. Measures introduced to curtail the spread of the virus come at potentially substantial economic cost. Importantly, many of these costs have been borne unequally, falling

\footnotetext{
*Submitted September 2020.

The authors thank Richard Blundell, Eric French, Rob Joyce and Fabien Postel-Vinay, along with the editor and two anonymous referees, for helpful comments. Piyapromdee gratefully acknowledges support from the European Research Council (grant reference ERC-2016-CoG-682349).

Keywords: COVID-19, consumption, income, household structures, mitigation policy.

JEL classification numbers: D1, H3, J2, J6.
} 
disproportionately on low-income and younger workers. What explains the inequality in labour market impacts? Given assortative partnering, how well can households self-insure against the risks? And to what extent are the most affected households able to maintain expenditure following any negative income shocks? The answers to these questions are crucial for designing and assessing policies to mitigate the economic costs of the pandemic.

In this paper, we use real-time nationally representative survey data from the UK to answer these questions. We analyse the source of observed inequalities in impacts of the pandemic by estimating the relationship between employment outcomes and three occupational and industry characteristics: physical proximity at the workplace, location flexibility of the job and industry exposure to reduced demand. To the best of our knowledge, this is the first paper to quantify this relationship. We then compare the effects of the UK's Coronavirus Job Retention Scheme (CJRS) and of an alternative relief programme similar to the Economic Impact Payments in the US, taking into account labour market disruption associated with occupational characteristics, assortative partnering and differences in households' assets. Our findings shed important light on features of effective mitigation policy.

We document substantial variation in labour market outcomes across workers. The likelihood of labour market disruption (being laid off or furloughed) falls over the earnings and asset distributions. Less-educated workers and those younger than 25 or older than 65 have also faced substantial disruption. At the household level, the relationship between labour market impacts and earnings is qualitatively similar to that at the individual level. However, in the bottom fifth of the earnings distribution, 23 per cent of singles are laid off while only 4 per cent of couples experience both partners being laid off; in the majority of cases, at least one partner either works as usual or is furloughed. This highlights the importance of partial insurance at the household level.

To understand sources of inequalities in the impact of the pandemic, we relate these outcomes to measures of physical proximity, flexibility to work from home and industry exposure to reduced demand during the pandemic across occupations and industries. Lower-earning workers are most likely to be in industries with reduced demand, and also have least flexibility to work remotely. This is the case too for lower-educated, the youngest and the oldest workers. Females are more likely to have jobs requiring close physical proximity than males. At the household level, exposure to reduced industry demand falls in the top half of the earnings distribution, and work flexibility rises substantially across both the earnings and asset distributions. These risks are also highly correlated between spouses, particularly among low-income households. This suggests that the occupational and industrial characteristics are important determinants of labour market impacts across workers and households. 
We quantify this relationship directly by estimating a probit model of employment outcomes (either working, furloughed or separated from the employer) on the physical proximity, location flexibility and industry exposure of a worker's job. We find that all three factors matter for the likelihood of being laid off, but only location flexibility and industry exposure are key predictors for being furloughed or working. This suggests that policy supporting furloughed workers should target those with inflexible working arrangements and those in the most exposed industries.

We then conduct a quantitative analysis of the impacts of COVID-19 on incomes and spending. Using an expenditure imputation method adapted from Blundell, Pistaferri and Preston (2008), we show that, despite the support from CJRS, the reduction in labour income leads to a shortfall between income and expenditure for lower-income households. Among these households, 70 per cent are unlikely to have sufficient assets to maintain expenditure for even one week. ${ }^{1}$ Our findings imply that the labour market effects of the pandemic are likely to widen inequalities in consumption and savings since lower-income households: (1) experience a larger proportionate income reduction; (2) have a smaller buffer between usual income and expenditure, and make smaller savings during lockdown; and (3) hold insufficient liquid assets to sustain expenditure. These facts explain why savings rates fell among low-income households but rose among high-income households during the pandemic. ${ }^{2}$

Finally, we compare the effectiveness of the UK's CJRS and of the very different mitigation policy in the US. CJRS pays 80 per cent of pre-pandemic earnings (up to a monthly cap) for furloughed workers. ${ }^{3}$ The US policy instead provides a one-off payment to all tax-filing households. The size of the payment reduces with pre-pandemic earnings and takes into account household characteristics such as the number of children. We find that the US-style payment would better enable households to maintain their usual expenditure. This is because: (1) the payment has full coverage, while CJRS does not cover laid-off workers; (2) the payment has a higher replacement rate for low-income workers, unlike the flat 80 per cent rate of CJRS (up to a cap); and (3) households with more children (which tend to have lower incomes) get higher payments. ${ }^{4}$

This paper is closely related to work studying heterogeneity in labour market exposure to lockdown measures. Much existing work uses

\footnotetext{
${ }^{1}$ Since the UK Household Longitudinal Study (UKHLS) COVID module does not provide information on current assets, we use information on household assets from UKHLS wave 8 (collected in 2016 and 2017).

${ }^{2}$ Haldane, 2020.

${ }^{3}$ The scheme has had substantial uptake, with over 30 per cent of the workforce supported by the scheme by 31 May 2020 (HM Revenue and Customs, 2020).

${ }^{4} \mathrm{~A}$ key objective of CJRS was to keep workers with their existing employer. While it is not yet possible to assess its effectiveness in achieving this objective, retaining employment relationships is likely to generate longer-term benefits.
} 
occupational characteristics to study the possible effects of COVID-19 on labour supply, focusing on income losses. Joyce and $\mathrm{Xu}$ (2020) and Blundell et al. (2020) document the characteristics of workers employed in sectors most likely to be affected by lockdown measures, based on pre-pandemic employment patterns. Hicks, Faulk and Devaraj (2020) study the physical proximity of occupations and Dingel and Neiman (2020) analyse work location flexibility, while Lekfuangfu et al. (2020) and Mongey, Pilossoph and Weinberg (2020) consider the interaction between these two factors. Del RioChanona et al. (2020) provide a quantitative prediction of both supply and demand across wage levels. ${ }^{5}$ However, the relationship between these ordinal indices of occupational characteristics and labour market disruption remains unstudied, making it difficult to understand policy implications.

Our paper is also related to literature documenting the impacts of lockdown measures in the UK. Delestre et al. (2020) use data on users of the Money Dashboard budgeting app to document impacts on income and spending, while Benzeval et al. (2020) use data from the UK Household Longitudinal Study (UKHLS) to document heterogeneity in the impacts. Adams-Prassl et al. (2020a) use survey data collected in early April to compare labour market impacts between the UK, the US and Germany.

We contribute to these literatures in four ways. First, we provide new empirical evidence on heterogeneity in labour market impacts of the pandemic, using nationally representative survey data from the UKHLS. In addition to the characteristics studied by Benzeval et al. (2020), we analyse impact differentials across the household asset distribution, and also consider the correlation in impacts between household members - both key determinants of households' ability to self-insure against the disruption. Second, this is the first paper to quantify the relationship between labour market outcomes and indices of occupational and industrial characteristics. Third, we analyse the implications of the pandemic for spending in addition to income for a nationally representative sample, as this may better reflect the true impact on household welfare. ${ }^{6}$ Our findings can explain the inverse relationship between changes in savings rates and households' incomes in Haldane (2020). Finally, we provide a comparative assessment of flagship policies implemented in the UK and the US to mitigate the impacts of the pandemic.

Additionally, our paper is related to the literature on household risk sharing and consumption. ${ }^{7}$ These papers highlight the role of family labour supply as partial insurance for consumption against income shocks. We show that couples are less affected by the pandemic than singles. This is because

\footnotetext{
${ }^{5}$ Their measure of demand shocks is based on pre-COVID-19 estimates from an influenza pandemic.

${ }^{6}$ Poterba, 1989; Cutler and Katz, 1992.

${ }^{7}$ For example, Attanasio et al. (2002), Blundell, Pistaferri and Preston (2008) and Heathcote, Storesletten and Violante (2014).
} 
correlation in the earnings shocks between partners is imperfect, providing for some partial insurance. However, the correlation between partners' labour market risks is highest for lower-income households, making them least able to self-insure.

Overall, this paper highlights the importance of differences in households' ability to cushion negative income shocks and sheds light on features of effective pandemic-mitigation policy. Our results suggest that, to effectively reduce the negative and uneven consequences of COVID-19 on household welfare, it is important to provide short-term liquidity (as the most affected households also have the lowest means to smooth consumption) and, in the longer term, provide a combination of income and employment support to workers with least flexibility to work from home and in industries with most reduced demand. This is particularly the case as affected workers tend to be young - losing the opportunity to accumulate human and social capitals at work could have long-term consequences for lifetime earnings.

\section{Data overview}

Our main data are drawn from the UK Household Longitudinal Study, a nationally representative longitudinal survey of individuals in the UK. We focus on the most recent wave (wave 9), collected in 2017 and 2018, and merge in detailed data on assets from a specialist survey module administered during wave 8 in 2016 and 2017. We use additional information on labour market outcomes during the pandemic from the first UKHLS supplemental COVID19 module (collected at the end of April 2020).

We focus on individuals who were working and over the age of 16 at the time of their wave 9 interview. We define occupations using the threedigit Standard Occupational Classification (SOC) code of their main job, and similarly define industries using top-level Standard Industrial Classification (SIC) codes. We define earnings as net labour income in the month before the individual was interviewed in wave $9 ;{ }^{8}$ then we define total income, which adds to earnings any benefit or other income. Finally, we construct liquid assets as the sum of savings and any funds held in investment accounts in UKHLS wave 8 .

The UKHLS data also include household expenditure on a small set of essential items in 2017 and 2018. To provide a more complete picture of household spending, we impute total household expenditure using detailed data on household spending drawn from the 2017-18 Living Costs and Food Survey (LCFS). We use a similar procedure to that in Blundell, Pistaferri and Preston (2008) by first estimating the demand for food (an expenditure item

\footnotetext{
${ }^{8}$ This includes usual pay from their main job, pay from any second jobs, and profits (or losses) from self-employment.
} 
available in both UKHLS and LCFS) as a function of total expenditure and household characteristics, and then inverting the estimated system to impute total expenditure for UKHLS sample members.

We drop workers who did not provide data on assets in wave 8 or have missing information about industry exposure. Our sample contains 13,225 residents in 9,639 households. We provide details on our data, including the expenditure imputation procedure, in Appendix A, available online.

\section{Labour market impacts of COVID-19}

The pandemic has disrupted labour markets along multiple dimensions. Given worker heterogeneity across occupations and industries, the impacts are likely to be uneven. In this section, we start by examining labour market outcomes at the individual and household levels. We then analyse the drivers of labour market outcomes. We relate outcomes to three labour market risks using a probit model. The first two - physical proximity and location flexibility - may lead to labour supply disruption. ${ }^{9}$ The third measure is associated with reduced labour demand. We find a clear relationship between these risks and labour market outcomes.

\section{Labour market outcomes}

We use data from the UKHLS COVID-19 module to study the labour market impacts of the pandemic. In addition to labour market status in April 2020, respondents provided their 'baseline' employment status in February 2020. We focus on people working at the baseline and identify those who, in April, were either working, furloughed on the CJRS or no longer employed.

Figure 1 shows these outcomes across workers' time-invariant characteristics. Panel a categorises by ethnicity on the left and by gender and education on the right. Black people are most likely to have kept their jobs ( 75 per cent) and least likely to have been laid off ( 8.1 per cent). Asian people are half as likely to be furloughed as other ethnicities (11 per cent versus around 20 per cent). However, Asian and mixed-race people are over twice as likely as black people to be laid off. In the right panel, we show that low-educated workers are more adversely affected than high-educated workers.

Panel $\mathrm{b}$ plots the outcomes by location (left side) and age (right side). Workers in London are least likely to have experienced labour market disruption, while those in the Midlands, Wales and Northern Ireland are most

\footnotetext{
${ }^{9}$ These have been used as possible predictors of labour market impacts of COVID-19 in a number of papers (although the relationship to outcomes remains unquantified) - for example, Dingel and Neiman (2020) for the location flexibility factor and Hicks, Faulk and Devaraj (2020) for the physical proximity factor.
} 
FIGURE 1

\section{Heterogeneity in labour market outcomes}

(a) Ethnicity (left) and gender-education (right)
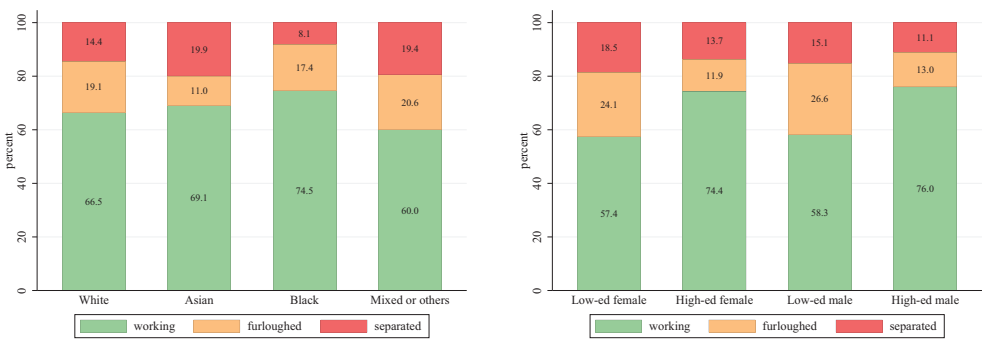

(b) Location (left) and age group (right)
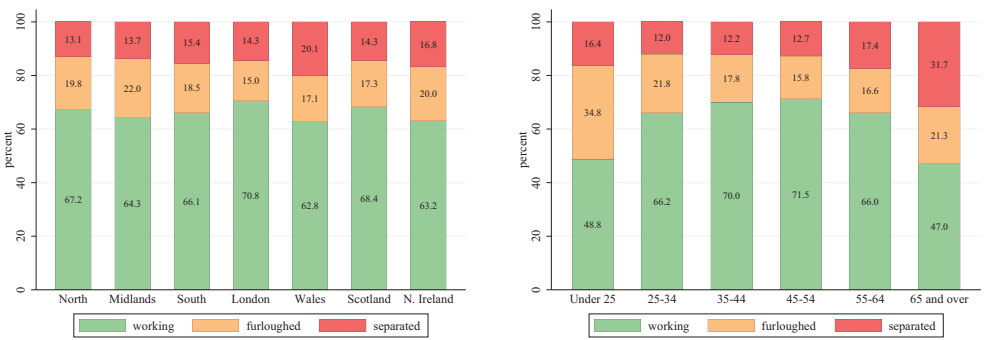

(c) Earnings (left) and assets (right)

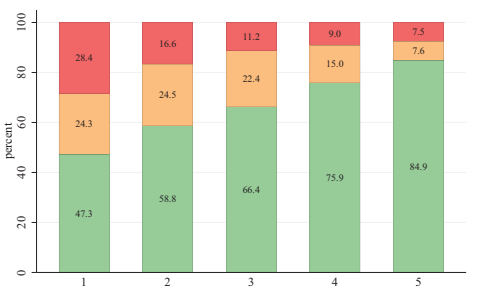

Individual's labour earnings quintile

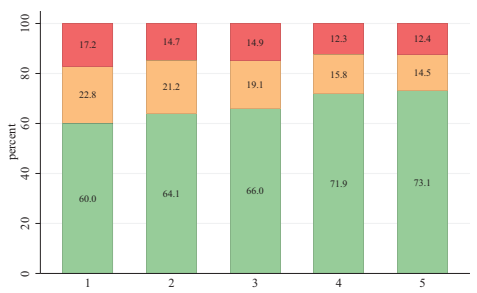

Individual's asset quintile
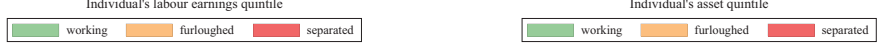

(d) Singles (left) and couples (right)
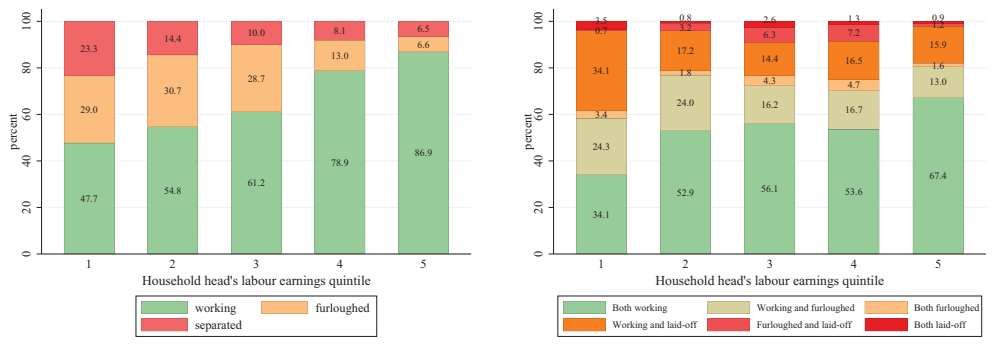

Note: High education is defined as having a university degree or higher. Panels a-c include employed workers in the baseline period of the COVID-19 supplementary sample. The right side of Panel d includes households with partners living together. Household head is defined as the higher-earning partner, and the household head's labour earnings quintile is calculated from the unconditional individual earnings distribution, comparable to the individual-level labour income quintiles in Panel c. 
disrupted. There are polarised impacts across ages. The youngest (under 25 years) and the oldest (65 years and over) are the most likely to experience labour market disruption. The disproportionate impact on young people is consistent with Costa Dias, Joyce and Norris Keiller (2020), who note the potentially severe impacts on long-term career prospects.

Panel c shows the outcomes by individuals' earnings (left) and assets (right). Lower-earning workers are much more affected than those with higher earnings. And workers with lower assets are also more likely to be disrupted. Finally, Panel $d$ shows the distribution of impacts at the household level by the earnings quintile of household heads, focusing on singles on the left and couples on the right. ${ }^{10}$ The relationship between labour market risk and earnings is qualitatively similar at the household level to that at the individual level. However, while 23 per cent of singles in the bottom fifth of the earnings distribution are laid off, both partners are laid off in only 4 per cent of couples in this quintile.

Overall, these plots provide evidence that workers at the bottom of both the earnings and asset distributions are most affected by labour market disruption caused by COVID-19, particularly singles who have no household-level risk sharing. This is likely to have important implications for their ability to smooth consumption. We return to this point in Section IV.

\section{Sources of outcome differential}

To analyse factors driving differences in labour market outcomes, we focus on three sources of risk. We adopt the physical proximity and location flexibility factors from Lekfuangfu et al. (2020), who construct these indices from $\mathrm{O}$ NET using factor analysis. ${ }^{11}$ The indices are continuous measures of location flexibility (or ability to work from home) and physical proximity for each of 900 detailed occupations, reflecting that these features are unlikely to be binary (as also noted by Adams-Prassl et al. (2020b)). Our third measure is an index of industry exposure based on the economic impact survey of the Office for National Statistics (2020). We use the percentage of businesses reporting to have temporarily closed in each industry, defined by its top-level SIC code, as an indicator of industry exposure. ${ }^{12}$ The measures of all three factors are standardised to have mean 0 and standard deviation $1 .{ }^{13}$

We first motivate our focus on these three factors. Panels a-c of Figure 2 show how each of the risks varies across age groups, conditional on gender and education. While there is limited variation in physical proximity by age, industry exposure and location flexibility exhibit a $U$ shape and an

\footnotetext{
${ }^{10} \mathrm{We}$ designate the higher-earning member of a cohabiting couple as the household head.

${ }^{11}$ For more details, see Lekfuangfu et al. (2020) and Appendix B, which is available online.

${ }^{12}$ See Table C1 in Appendix C, available online. Due to some industries having an insufficient number of firms responding to the ONS survey, this measure is available for only 12 of 21 top-level SIC codes,
} 


\section{FIGURE 2}

Work characteristics by gender and education
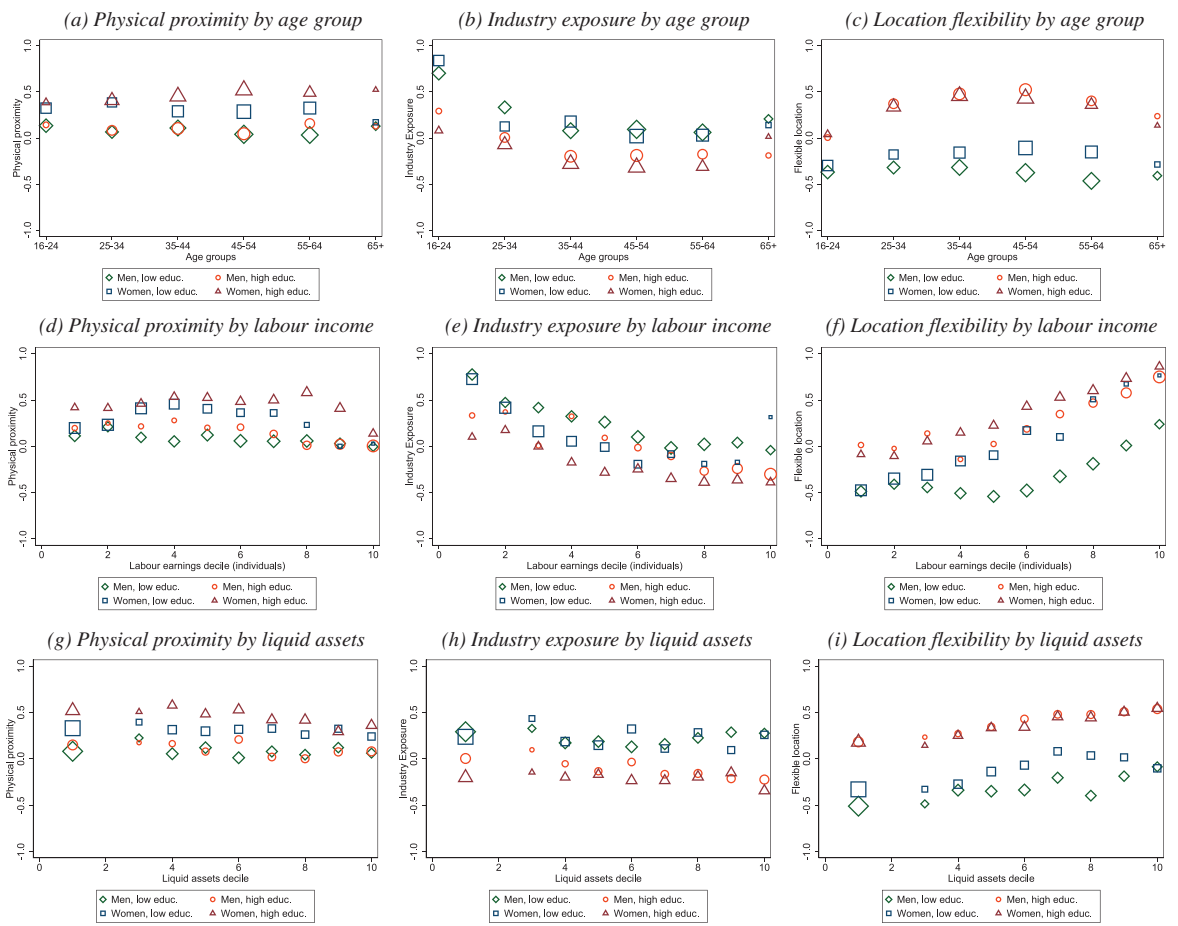

Note: High education is defined as having a university degree or higher. Marker size reflects employment counts relative to the unconditional individual earnings distribution (meaning that sizes are comparable across subfigures). Sample includes all employed workers in the main UKHLS sample.

inverse-U shape, respectively. This implies that youngest and oldest workers may be most adversely affected by the pandemic due to the inflexibility of their jobs and demand disruption within their industries. And these undesirable characteristics of jobs are also most prevalent among low-educated workers across all age groups.

Panels $\mathrm{d}-\mathrm{f}$ show the measures across earnings deciles. On the one hand, physical proximity varies only modestly across the earnings distribution and types of workers. On the other hand, location flexibility and industry exposure vary substantially: lower-earning workers (particularly low-educated males) are most likely to be in industries exposed to demand reductions and with

representing 82 per cent of the UK workforce. We have dropped individuals whose industry is missing from the ONS survey from our analysis.

${ }^{13}$ Specifically, the measures have mean 0 and standard deviation 1 across unweighted occupations and industries. 
FIGURE 3

Within-household correlation between exposure measures

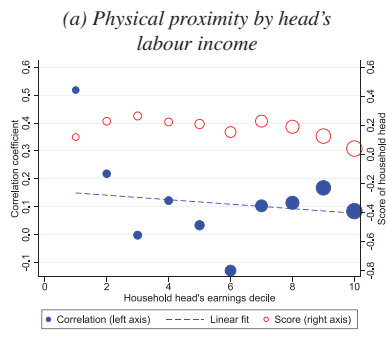

(d) Physical proximity by liquid assets

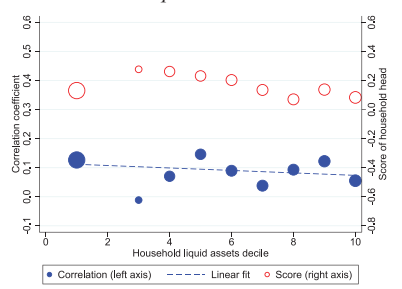

(b) Industry exposure by head's labour income

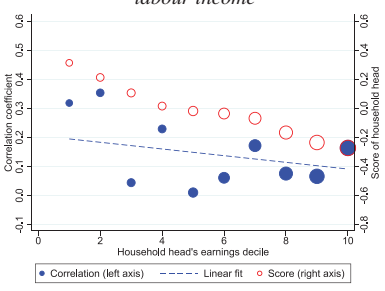

(e) Industry exposure by liquid assets

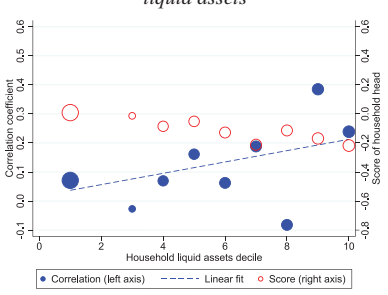

(c) Location flexibility by head's labour income

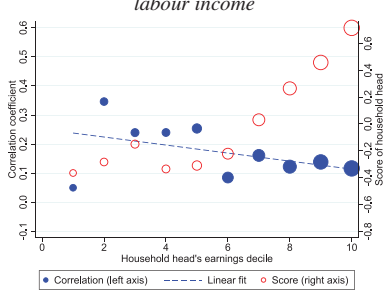

(f) Location flexibility by liquid assets

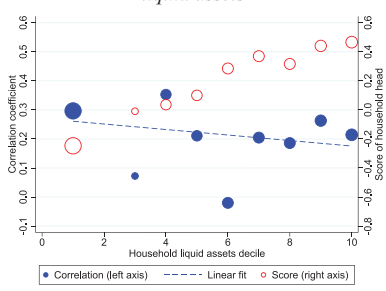

Note: The figure shows the correlation between partners' values of each exposure measure (left axis) and score of the exposure measure for the household head (right axis). Household head is defined as the higherearning partner. Marker size reflects the number of household heads in each decile of the unconditional individual earnings distribution (including singles and partners of heads). Sample includes all employed spouses in the main UKHLS sample.

least flexibility to work remotely. This is consistent with patterns observed in other countries. ${ }^{14}$ Finally, Panels g-i show the measures along the distribution of liquid assets. Low-educated workers are most exposed to negative demand shocks, and also have relatively low liquid assets (as indicated by the size of markers).

Assortative partnering between people with similar education levels further amplifies the unequal distribution of risks at the household level. Figure 3 shows the within-couple correlations of each factor (on the left vertical axis), and the average score of the household head for a given factor (the right vertical axis). The marker size in this figure represents the number of household heads in each decile of the individual earnings distribution. Panels a-c show spousal correlations by the household head's earnings, and Panels $\mathrm{d}-\mathrm{f}$ show similar statistics along the distribution of household liquid assets.

While there is little difference in the average degree of physical proximity across the household head's earnings distribution, the average degree of

\footnotetext{
${ }^{14}$ For example, Mongey, Pilossoph and Weinberg (2020) for the US, Saltiel (2020) and Lekfuangfu et al. (2020) for developing countries.
} 
work flexibility rises substantially in the top half of the distribution and the average degree of industry exposure declines gradually in earnings. That is, low-earnings households are more likely to experience unfavourable shocks to labour supply and demand. Further, these risks are positively correlated between spouses because they tend to work in similar occupations and industries, particularly at the bottom end of the earnings distribution.

Additionally, Panels $\mathrm{d}-\mathrm{f}$ of Figure 3 show that the average degree of the household head's physical proximity does not vary much by the household's liquid assets. However, the degree of industry exposure is slightly declining in the household's assets, with a higher positive correlation among spouses in wealthy families. The degree of work flexibility of the household head is substantially lower at the bottom end of the asset distribution and it is more correlated between spouses than the other measures. Overall, these plots demonstrate that households at the bottom of both the earnings and asset distributions are most exposed to labour market risks.

To quantify the effects of these risks, we estimate the probability of three labour market outcomes - working as usual, being furloughed and not working - as a function of the three risks using a multinomial probit model. ${ }^{15}$ For each of the three labour market outcomes, we write

$$
y_{i j}=\boldsymbol{\alpha}_{j} \mathbf{f}_{i}+\boldsymbol{\beta} \mathbf{x}_{i}+\xi_{i j},
$$

where $j=$ \{working, furloughed, separated $\}, y_{i j}$ is the latent labour market outcome variable of worker $i, \mathbf{f}_{i}$ is a vector containing the three factors and their interactions based on the individual's occupation and industry in the prepandemic period, $\mathbf{x}_{i}$ contains individual $i$ 's characteristics such as age, and $\xi_{i j} \stackrel{i i d}{\sim} \mathrm{N}(0,1)$ is an idiosyncratic shock.

Table 1 reports the estimated marginal effects of each factor, holding other variables at their means. The marginal effects are robust across specifications. On average, a 1-unit increase in physical proximity increases the probability of being laid off by around 4 percentage points, but has no statistically significant impact on the probability of being furloughed. By contrast, a 1-unit increase in location flexibility reduces the lay-off probability by around 5.5 percentage points and the furlough probability by around 3 percentage points. Finally, a 1 -unit increase in industry exposure increases the lay-off probability by around 2 percentage points, but increases the furlough probability by 7 to 8 percentage points. ${ }^{16}$ Overall, workers with least location flexibility, in jobs requiring high physical proximity and in industries with most reduced demand are most likely

\footnotetext{
${ }^{15}$ The net benefits of the employment outcomes to firms may not have global ordering. Therefore, we consider a multinomial probit to be more appropriate than an ordered probit model.

${ }^{16}$ We plot the distribution of these marginal effects for model 3 in Figure D1 in Appendix D, available online.
} 
TABLE 1

Marginal effects of indices on labour market outcomes

\begin{tabular}{|c|c|c|c|c|c|}
\hline & Model 1 & Model 2 & Model 3 & Model 4 & Model 5 \\
\hline \multicolumn{6}{|l|}{ Physical proximity } \\
\hline Working & $\begin{array}{l}-0.0253 \\
(-1.47)\end{array}$ & $\begin{array}{l}-0.0285 \\
(-1.62)\end{array}$ & $\begin{array}{l}-0.0251 \\
(-1.42)\end{array}$ & $\begin{array}{l}-0.0255 \\
(-1.45)\end{array}$ & $\begin{array}{l}-0.0248 \\
(-1.40)\end{array}$ \\
\hline Furlough & $\begin{array}{l}-0.0200 \\
(-1.42)\end{array}$ & $\begin{array}{l}-0.0128 \\
(-0.89)\end{array}$ & $\begin{array}{l}-0.0131 \\
(-0.91)\end{array}$ & $\begin{array}{l}-0.0140 \\
(-0.98)\end{array}$ & $\begin{array}{l}-0.0156 \\
(-1.07)\end{array}$ \\
\hline Laid off & $\begin{array}{l}0.0452^{* * *} \\
(3.92)\end{array}$ & $\begin{array}{l}0.0413^{* * *} \\
(3.45)\end{array}$ & $\begin{array}{l}0.0382^{* *} \\
(3.20)\end{array}$ & $\begin{array}{l}0.0395^{* *} \\
(3.25)\end{array}$ & $\begin{array}{l}0.0404^{* * *} \\
(3.35)\end{array}$ \\
\hline \multicolumn{6}{|l|}{ Industry exposure } \\
\hline Working & $\begin{array}{l}-0.0987^{* * *} \\
(-7.83)\end{array}$ & $\begin{array}{l}-0.0930^{* * *} \\
(-7.36)\end{array}$ & $\begin{array}{l}-0.0900^{* * *} \\
(-7.16)\end{array}$ & $\begin{array}{l}-0.0894^{* * *} \\
(-7.20)\end{array}$ & $\begin{array}{l}-0.0907^{* * *} \\
(-7.31)\end{array}$ \\
\hline Furlough & $\begin{array}{l}0.0775^{* * *} \\
(7.75)\end{array}$ & $\begin{array}{l}0.0722^{* * *} \\
(7.23)\end{array}$ & $\begin{array}{l}0.0704^{* * *} \\
(7.09)\end{array}$ & $\begin{array}{l}0.0707^{* * *} \\
(7.18)\end{array}$ & $\begin{array}{l}0.0702^{* * *} \\
(7.09)\end{array}$ \\
\hline Laid off & $\begin{array}{l}0.0211^{*} \\
(2.48)\end{array}$ & $\begin{array}{l}0.0208^{*} \\
(2.42)\end{array}$ & $\begin{array}{l}0.0195^{*} \\
(2.33)\end{array}$ & $\begin{array}{l}0.0187^{*} \\
(2.19)\end{array}$ & $\begin{array}{l}0.0205^{*} \\
(2.51)\end{array}$ \\
\hline \multicolumn{6}{|l|}{ Location flexibility } \\
\hline Working & $\begin{array}{l}0.111^{* * *} \\
(7.15)\end{array}$ & $\begin{array}{l}0.0882^{* * *} \\
(5.40)\end{array}$ & $\begin{array}{l}0.0848^{* * *} \\
(5.18)\end{array}$ & $\begin{array}{l}0.0843^{* * *} \\
(5.16)\end{array}$ & $\begin{array}{l}0.0783^{* * *} \\
(4.77)\end{array}$ \\
\hline Furlough & $\begin{array}{l}-0.0565^{* * *} \\
(-4.34)\end{array}$ & $\begin{array}{l}-0.0327^{*} \\
(-2.37)\end{array}$ & $\begin{array}{l}-0.0309^{*} \\
(-2.25)\end{array}$ & $\begin{array}{l}-0.0314^{*} \\
(-2.28)\end{array}$ & $\begin{array}{l}-0.0273^{*} \\
(-1.97)\end{array}$ \\
\hline Laid off & $\begin{array}{l}-0.0542^{* * *} \\
(-5.05)\end{array}$ & $\begin{array}{l}-0.0555^{\text {*** }} \\
(-4.95)\end{array}$ & $\begin{array}{l}-0.0538^{* * *} \\
(-4.78)\end{array}$ & $\begin{array}{l}-0.0529^{* * *} \\
(-4.72)\end{array}$ & $\begin{array}{l}-0.0510^{* * *} \\
(-4.53)\end{array}$ \\
\hline \multicolumn{6}{|l|}{ Controls } \\
\hline Gender & & $\checkmark$ & $\checkmark$ & $\checkmark$ & $\checkmark$ \\
\hline Education & & $\checkmark$ & $\checkmark$ & $\checkmark$ & $\checkmark$ \\
\hline Age and age squared & & & $\checkmark$ & $\checkmark$ & $\checkmark$ \\
\hline Regional dummy & & & & $\checkmark$ & $\checkmark$ \\
\hline Ethnicity & & & & & $\checkmark$ \\
\hline Sample size & 3,258 & 3,258 & 3,258 & 3,258 & 3,229 \\
\hline AIC & $4,894.7$ & $4,852.6$ & $4,827.4$ & $4,839.6$ & $4,770.4$ \\
\hline BIC & $4,992.1$ & $4,974.3$ & $4,973.5$ & $5,131.8$ & $5,098.7$ \\
\hline
\end{tabular}

Note: The table shows marginal effects at means. $z$-scores are given in parentheses. $* * *, * *$ and $*$ signify $p$-value $<0.01, p$-value $<0.05$ and $p$-value $<0.1$, respectively. AIC and BIC refer to Akaike and Bayes Information Criteria. Sample includes employed workers in the baseline period of UKHLS COVID-19 module.

to experience labour market disruption during the pandemic. Policy aimed at mitigating the impacts on incomes should therefore target these workers.

\section{Effects on income and spending}

We now consider the consequences of the labour market risks for households' income and spending. To quantify these effects, we first calculate the expected 
income of each individual in a household during the pandemic, based on the estimated probabilities of labour market disruption. ${ }^{17}$ For each individual in our sample, we calculate expected monthly labour earnings during the pandemic, $y_{\text {covid }}$, as

$$
\begin{aligned}
y_{\text {covid }}= & \left(\operatorname{Pr}(\text { working }) \times y_{\text {pre }}\right)+\left(\operatorname{Pr}(\text { furloughed }) \times y_{\mathrm{f}}\right) \\
& +\left(\operatorname{Pr}(\text { separated }) \times y_{\mathrm{s}}\right),
\end{aligned}
$$

where $y_{\text {pre }}$ is earnings in the pre-pandemic period, $y_{f}$ is earnings if furloughed and $y_{s}$ is earnings if separated. ${ }^{18}$ In this section, we first examine the effects of the pandemic on household income across the income distribution. We then consider the extent to which reduced income affects households' ability to meet their expenditure requirements. Finally, we discuss households' ability to maintain expenditure using liquid assets.

\section{Income}

We assume that the earnings of individuals who continue working are unchanged compared with the pre-crisis period, $y_{\text {pre }}$, as measured in wave 9 of UKHLS during 2017 or 2018. Earnings of separated workers, $y_{s}$, fall to zero, and earnings of furloughed workers, $y_{f}$, are supported by the CJRS, under which the government pays 80 per cent of their usual earnings up to a cap of $£ 2,500$ a month before taxes (around $£ 2,000$ net). We then define total income as earnings plus other incomes. For couples, total household income is the sum of each individual's total income. ${ }^{19}$ We allow for increases to universal credit - the main benefit supporting unemployed or low-income households - if earnings fall. To reflect the typical minimum wait between claiming and receiving universal credit, we assume that households only receive additional payments after five weeks. We hold all other unearned income an individual received in 2017-18 fixed.

We show the impact of COVID-19 on household income for couples in Panel a and for singles in Panel b of Figure 4. Within each income quintile, the left-most bars show median monthly household income per person before the pandemic across quintiles of the income distribution; the middle bars show expected household income during the pandemic before adjustments to universal credit; and the right-most bars include any increased universal credit. For both couples and singles, the absolute reduction in per-person household

\footnotetext{
${ }^{17}$ We select model 3 from Table 1 as our preferred specification, based on its AIC and BIC.

${ }^{18}$ This approach allows us to include the full UKHLS wave 9 sample in our analysis, rather than the subset of people who responded to the COVID-19 module.

${ }^{19} \mathrm{We}$ drop households containing non-family members as they may not share resources within households and we exclude children's earnings from household income.
} 
FIGURE 4

Effect on income

(a) Couples

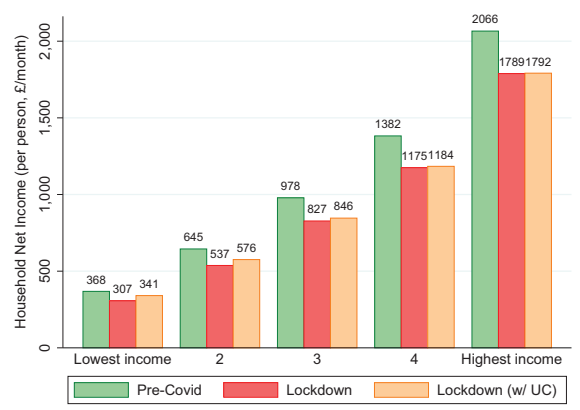

(b) Singles

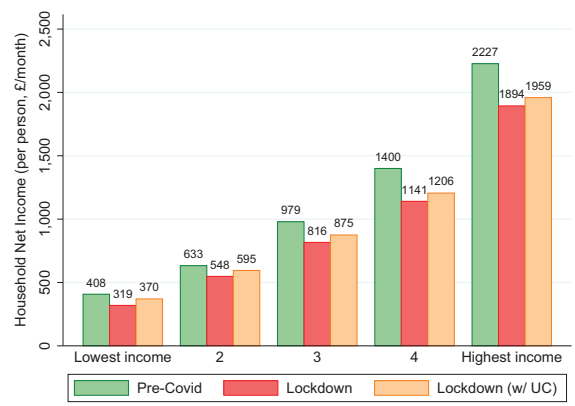

Note: Panel a shows median per-person net household total income for couples in each quintile of the (per-person) household income distribution. Panel $\mathrm{b}$ shows the same statistics for singles.

income is larger for higher-earning households. However, the proportionate reduction in income is highest for low-income households before adjustments to universal credit. For couples, median per-person household income falls by 17 per cent in the bottom earnings quintile compared with 13 per cent in the top; similarly, the reduction is 22 per cent for singles in the bottom quintile and 15 per cent for those in the top. This highlights that the labour market impacts of the pandemic fall disproportionately on low-income households. And, while universal credit mitigates these unequal income effects, we show in the next subsection that there remains inequality in the ability of households to absorb reduced income.

\section{Expenditure}

We now consider the effect of these income reductions on households' ability to finance expenditure where households' expenditures are imputed using Blundell, Pistaferri and Preston (2008)'s technique. ${ }^{20}$ We present the expected gap between income and expenditure for couples in Panel a and for singles in Panel $b$ of Figure 5. ${ }^{21}$ In these panels, we show 'short-term' incomeexpenditure gaps per household member, before any additional support from universal credit. ${ }^{22}$ Within each quintile, the left-most bars show the median gap

\footnotetext{
${ }^{20}$ Expenditure includes all types of spending, reflecting that a household may have financial commitments in addition to spending on consumption items.

${ }^{21}$ We note also that, while producing consistent estimates, our imputation procedure is likely to introduce measurement error into the expenditure data. To mitigate the impact on our conclusions of outliers arising from measurement error, in this section we focus on median income-expenditure gaps.

${ }^{22}$ The deficits become slightly smaller when we include universal credit (see Figure D3 in Appendix D, available online), but remain larger than before the pandemic.
} 
FIGURE 5

Income-expenditure gap

(a) Couples

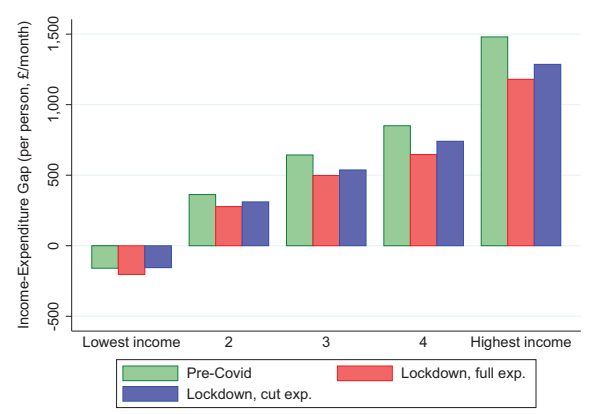

(b) Singles

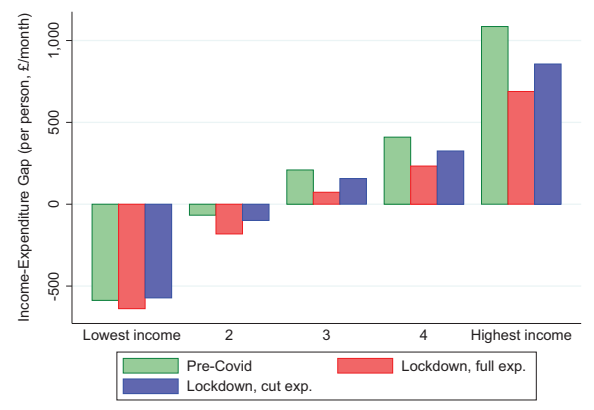

Note: Panel a shows the median gap between income and expenditure (per person) for couples, both in the pre-COVID period and under the two scenarios described in the text. Panel b shows the same statistics for singles.

before the pandemic. This is increasing in household income, suggesting that higher-income households are better able to absorb a reduction in income. ${ }^{23}$ The middle bars show the expected income-expenditure gaps during the pandemic. For couples, the reduction in income increases the pre-existing income-expenditure deficit for those in the bottom quintile, and reduces the income-expenditure surplus over the rest of the distribution (although the gaps remain positive). For singles, the pre-existing income-expenditure deficits increase in the bottom 40 per cent. Therefore, despite the support from the CJRS, the labour market impacts of the pandemic jeopardise the ability of the lowest-income households to afford their usual spending, and the effects are particularly severe for singles.

However, as a result of increased restrictions, household spending may have fallen during the pandemic. We construct a second measure of total expenditure that reduces spending on categories for which spending is likely to have fallen as a result of lockdown measures. ${ }^{24}$ We show the gap between household income during the pandemic and this reduced expenditure in the right-most bars within each quintile of Figure 5. The income-expenditure gap returns to around the pre-pandemic level for couples and singles in the bottom 20 per cent of the income distribution, but reduced spending fails

\footnotetext{
${ }^{23} \mathrm{We}$ also note that the pre-pandemic income-expenditure gap is negative for lower-income households. The observation that median household income exceeds expenditure for the lowest-income households is consistent with other studies - for example, Brewer, Goodman and Leicester (2006) for Britain and Pew Charitable Trusts (2016) for the US.

${ }^{24} \mathrm{We}$ exclude any spending on restaurants, hotels and leisure activities, and reduce spending on transport by 80 per cent reflecting that, across modes, transport use fell by between 70 per cent (for car travel) and 95 per cent (for rail travel) (Cabinet Office, 2020).
} 
to compensate reduced income for other groups. We note, however, that higher-income households make larger savings on usual expenditure during the pandemic since they usually spend more on expenditure items likely to be unavailable.

\section{Using assets to maintain expenditure}

We now analyse the extent to which the households whose incomeexpenditure gap becomes negative (or more negative) have sufficient savings to maintain spending. ${ }^{25} \mathrm{We}$ consider the three groups whose median incomeexpenditure gap becomes more negative as a result of the pandemic: couples in the bottom quintile of the earnings distribution, and singles in the first two quintiles. We calculate the number of weeks each household in these groups could finance the increase in the median gap based on pre-pandemic expenditure using their liquid assets. ${ }^{26}$

We incorporate an increase in income from universal credit after five weeks, reflecting the typical minimum wait between claiming and receiving universal credit. We focus attention on the number of households able to finance the median income-expenditure gap from liquid assets for (a) less than one week, (b) less than five weeks, (c) less than twelve weeks and (d) twelve weeks or more. Households in categories (a) and (b) are of particular policy interest, as these highly constrained households may not be able to sustain spending until receiving any increased benefit entitlement. We show the proportions of households in each of these categories in Figure 6.

Based on the most recently available asset data for individuals in our sample, collected in UKHLS wave 8, a substantial fraction of households are unlikely to have sufficient liquid assets to finance the median incomeexpenditure gap for even one week. This is true across all three groups. For couples in the bottom quintile of the income distribution, around 78 per cent would be unable to maintain expenditure for the five weeks before receiving any increased benefit payments. The equivalent figures are 70 per cent and 73 per cent for singles in the first and second quintiles. This underlines that a substantial fraction of the households whose income falls below their usual expenditure are likely to need to reduce spending as a result.

In summary, the labour market effects of the pandemic are likely to widen inequalities in consumption and savings since lower-income households:

\footnotetext{
${ }^{25}$ We summarise the distribution of liquid assets across income quintiles, separately for couples and singles, in Figure A1 in Appendix A, available online.

${ }^{26}$ We take the median income-expenditure gaps based on pre-pandemic expenditure as a reference point for each income group, instead of the reduced lockdown expenditure, as the latter may understate households' actual expenditure needs: it simply removes some items without allowing households to substitute this consumption into other categories. While modelling consumption responses (which could depend on households' incomes, beliefs and preferences) would be an interesting extension, it is beyond the scope of this paper.
} 
FIGURE 6

Weeks of expenditure sustainable using liquid assets

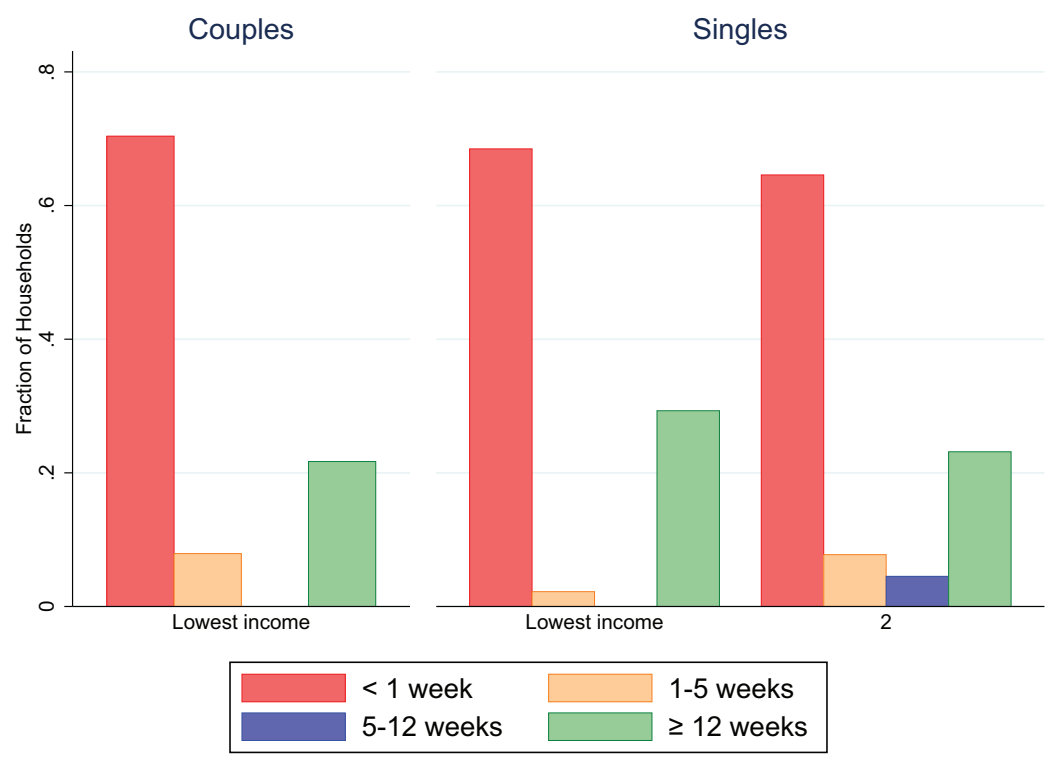

Note: The figure shows, for households in income quintiles with a negative median income-expenditure gap in our scenario, the lengths of time they could afford to maintain pre-pandemic expenditure by using liquid assets. Specifically, it shows the distribution of households' liquid assets divided by the median income-expenditure gap for their income quintile and status as a couple or single, defined using the pre-pandemic expenditure measure (i.e. the middle bars in Figure 5). For groups with a negative median income-expenditure gap before the pandemic, we instead divide liquid assets by the increase in the incomeexpenditure gap (i.e. the difference between the middle and left-most bars in Figure 5).

(1) experience a larger proportionate income reduction because of the types of jobs they do; (2) have a smaller buffer between usual income and expenditure, and make smaller savings during lockdown; and (3) do not hold sufficient assets to sustain expenditure. These results explain why savings rates fell among low-income households, but rose among high-income households, during the pandemic in the UK. ${ }^{27}$

\section{Alternative policy response}

\section{US-style economic impact payments}

In this section, we consider an alternative scheme, based on the Economic Impact Payments (EIPs) in the US. EIPs provide a one-off payment to all

\footnotetext{
${ }^{27}$ Haldane, 2020.
} 
households that file a tax return, up to a maximum of $\$ 1,200$ for each adult household member and $\$ 500$ for every child. The payments are reduced at a rate of $\$ 5$ for every $\$ 100$ earned above a threshold which depends on household structure.

This policy has a number of important differences from the CJRS. First, the payments are a one-off transfer rather than a recurring earnings replacement. The generosity of the EIPs therefore falls over time. Second, the EIPs are available to all households, whereas CJRS is only available to furloughed workers - not those continuing to work, nor those who are laid off. Finally, the lowest-income households are entitled to the highest EIP, unlike the 80 per cent replacement rate (up to a monthly cap) under CJRS.

We study the likely effects of an EIP-style payment in the UK. We set the maximum payment to $£ 593$ per adult and $£ 247$ per child. These amounts are equal to 1.0 and 0.4 times average weekly household expenditure in the UK, the same level as the EIPs relative to average household spending in the US. ${ }^{28}$ We then reduce the payments by 5 pence for every pound of gross household labour income above £4,031 a month for couples and £1,916 a month for singles. These thresholds are the $60^{\text {th }}$ percentile of the household income distributions for couples and singles in our sample, corresponding to the approximate location of the EIP thresholds in the US income distribution.

Unlike the CJRS, EIPs do not provide firms with assistance in retaining workers. ${ }^{29}$ In the absence of CJRS, it is likely that some furloughed workers would have lost their jobs. We consider three scenarios intended to capture the full range of potential outcomes: (1) all furloughed workers would have instead been laid off; (2) furloughed workers would have either separated from their employer or continued to work, with equal probability; and (3) all furloughed workers would have continued to work. These represent worst-, mid- and bestcase scenarios for the counterfactual outcomes of furloughed workers in the absence of CJRS.

\section{Comparison between US- and UK-style support}

In Table 2, we show the impacts of the policies on households' ability to maintain expenditure. We also consider a 'no policy' scenario, in which the labour market impacts are identical to the worst-case EIP scenario but workers receive no additional support from the government. Across all scenarios,

\footnotetext{
${ }^{28}$ US Bureau of Labor Statistics, 2019.

${ }^{29}$ There is a small Employee Retention Credit available in the US, providing a credit of 50 per cent of wages paid up to $\$ 10,000$ from March to December 2020. However, the scheme is less generous than the UK's CJRS - particularly as it requires employers to continue paying wages.
} 
TABLE 2

Effects of policies on expenditure

\begin{tabular}{l|c|c|ccc}
\hline & & & \multicolumn{3}{|c}{ US EIP } \\
\cline { 4 - 6 } & No & UK & Best & Mid & Worst \\
& policy & CJRS & case & case & case \\
\hline
\end{tabular}

Panel A. Maintain expenditure with liquid assets

\begin{tabular}{l|c|c|ccc}
\hline$<1$ week & $18.2 \%$ & $15.9 \%$ & $0.0 \%$ & $0.0 \%$ & $0.1 \%$ \\
$1-5$ weeks & $2.9 \%$ & $1.1 \%$ & $0.2 \%$ & $1.3 \%$ & $4.0 \%$ \\
$5-12$ weeks & $1.8 \%$ & $1.5 \%$ & $1.5 \%$ & $5.5 \%$ & $4.7 \%$ \\
$\geq 12$ weeks & $14.6 \%$ & $15.5 \%$ & $29.8 \%$ & $28.0 \%$ & $27.7 \%$ \\
No expenditure gap & $62.4 \%$ & $65.9 \%$ & $68.4 \%$ & $65.1 \%$ & $63.4 \%$ \\
\hline
\end{tabular}

Panel B. Average expenditure per individual (pre-COVID mean $=£ 1,652)$

\begin{tabular}{l|l|l|lll}
\hline After 1 week & $£ 1,593$ & $£ 1,623$ & $£ 1,652$ & $£ 1,652$ & $£ 1,651$ \\
After 5 weeks & $£ 1,603$ & $£ 1,629$ & $£ 1,651$ & $£ 1,644$ & $£ 1,629$ \\
After 12 weeks & $£ 1,595$ & $£ 1,623$ & $£ 1,647$ & $£ 1,627$ & $£ 1,611$
\end{tabular}

Panel C. Income gradient of expenditure reduction

\begin{tabular}{|c|c|c|c|c|c|}
\hline After 1 week & $\begin{array}{l}-1.987 \\
(0.384)\end{array}$ & $\begin{array}{l}-0.810 \\
(0.174)\end{array}$ & $\begin{array}{l}-0.007 \\
(0.001)\end{array}$ & $\begin{array}{l}-0.013 \\
(0.002)\end{array}$ & $\begin{array}{c}0.028 \\
(0.020)\end{array}$ \\
\hline After 5 weeks & $\begin{array}{l}-0.603 \\
(0.264)\end{array}$ & $\begin{array}{l}-0.330 \\
(0.133)\end{array}$ & $\begin{array}{c}0.047 \\
(0.010)\end{array}$ & $\begin{array}{c}0.270 \\
(0.094)\end{array}$ & $\begin{array}{c}0.559 \\
(0.195)\end{array}$ \\
\hline After 12 weeks & $\begin{array}{l}-0.444 \\
(0.280)\end{array}$ & $\begin{array}{l}-0.142 \\
(0.147)\end{array}$ & $\begin{array}{c}0.158 \\
(0.062)\end{array}$ & $\begin{array}{c}0.437 \\
(0.174)\end{array}$ & $\begin{array}{c}0.651 \\
(0.248)\end{array}$ \\
\hline \multicolumn{6}{|c|}{ Panel D. Cost per household } \\
\hline $\begin{array}{l}\text { After } 1 \text { week } \\
\text { After } 5 \text { weeks } \\
\text { After } 12 \text { weeks }\end{array}$ & $\begin{array}{l}£ 0 \\
£ 0 \\
£ 0\end{array}$ & $\begin{array}{c}£ 100 \\
£ 499 \\
£ 1,198\end{array}$ & $\begin{array}{l}£ 913 \\
£ 913 \\
£ 913\end{array}$ & $\begin{array}{l}£ 913 \\
£ 913 \\
£ 913\end{array}$ & $\begin{array}{l}£ 913 \\
£ 913 \\
£ 913\end{array}$ \\
\hline
\end{tabular}

Note: The table compares the effects of various policy options on households' ability to maintain expenditure during the COVID-19 pandemic. In each column, we consider a scenario in which the labour market disruption a worker faces depends on their estimated probabilities of continuing to work, being furloughed or separating from their employer. In all five columns, we assume workers also receive support from the UK welfare system after five weeks. See the text for details. The numbers in parentheses in Panel $\mathrm{C}$ are standard errors.

households may also become entitled to additional support from universal credit after five weeks. ${ }^{30}$

In Panel A of Table 2, we show the fraction of households that can sustain pre-pandemic expenditure using liquid assets for different lengths of time. With no policy intervention, 62 per cent of households would retain income

\footnotetext{
${ }^{30}$ In response to the pandemic, the UK government introduced a system of universal credit 'advances' designed to reduce this wait period. However, less than two in five new claimants in March, April and May received an advance payment (Department for Work and Pensions, 2020).
} 
above their usual expenditure. However, over 18 per cent would need to cut expenditure within one week.

CJRS partially mitigates the adverse effects. The fraction of households able to sustain expenditure indefinitely increases to 66 per cent and the fraction needing to cut spending within one week falls to 16 per cent. However, the EIP-style scheme is much more effective at supporting expenditure in the short term, reducing the fraction of households unable to sustain expenditure for one week to almost zero across all three scenarios. This highlights the severity of liquidity constraints for the households most affected by the pandemic, which the EIP is effective at relaxing.

In Panel $\mathrm{B}$, we consider the effects of the policies on average total expenditure per household member. We assume that households reduce expenditure if (a) their income falls below pre-pandemic expenditure (or any pre-existing income-expenditure deficit increases) and (b) their assets are insufficient to finance the shortfall for one, five or twelve weeks. We also report pre-pandemic average expenditure of $£ 1,652$ per household member.

While both CJRS and EIP mitigate the reduction, the EIP is more effective, at least in the short term. The worst-case EIP scenario generates the same average expenditure reduction as CJRS after five weeks. In the bestcase scenario, expenditure is barely affected. This highlights the potentially substantial short-term benefits of providing constrained households with liquidity. However, over longer time horizons, the continued support provided by the UK's CJRS becomes increasingly beneficial: by 12 weeks, the expenditure reduction under CJRS is similar to that of the mid-case EIP.

In Panel $\mathrm{C}$, we assess how each policy affects the pattern of expenditure reductions over the income distribution. We report the estimated coefficient from a linear regression of the percentage reduction in household spending on pre-pandemic household income (expressed in logs). ${ }^{31}$ A negative coefficient indicates that the percentage expenditure reduction is smaller for higherincome households, while a positive coefficient indicates the opposite. Across all scenarios, the gradients become less negative (or more positive) over time. This reflects that the very short-term effects on expenditure are concentrated on the lowest-income households because they have less of a buffer. And, at every point in time, CJRS mitigates the income gradient of expenditure effects compared with the no-policy scenario.

However, the EIP is more effective at eliminating the relationship between household income and the effect on expenditure. In fact, by five and twelve weeks, the estimated relationship between expenditure reductions and household income is positive. There are three main reasons for this. First, the EIP is highest for low-income households; by contrast, CJRS pays a fixed proportion of earnings (up to a cap). Second, EIPs depend on household

\footnotetext{
${ }^{31}$ We include all households in our sample, including those with no required spending reduction.
} 
structure (including number of children), which is related to household income (see Figure D2 in Appendix D, available online). Finally, all households are entitled to receive the EIP, including those with laid-off workers, unlike CJRS.

In Panel D of Table 2, we consider the cost per household of the CJRS and EIP payments. The cost of CJRS per household is higher than the cost of EIP by 12 weeks. But, despite its cost, it does not perform substantially better at supporting expenditure over this period. However, we note that the net benefits of CJRS relative to EIP would depend on the duration of the programme and whether it has longer-term benefits in helping workers retain their jobs.

\section{Conclusion}

This paper assesses the implications of the labour market disruption caused by COVID-19 for households in the UK. Workers with already low labour force attachment, such as those with lower education, are most adversely affected. The impacts are also concentrated on households at the bottom of the earnings and asset distributions. We provide evidence that occupational and industrial characteristics explain inequalities in earnings risk. These characteristics capture the impact of the pandemic on both labour supply (as measured by flexibility to work from home) and labour demand.

We then consider the consequences of this differential exposure for incomes and expenditure. Lower-income households experience the largest proportionate income reduction. This, along with a smaller buffer between usual income and expenditure, contributes to a shortfall between income and required expenditure for lower-income households, but not for higher-income households. Moreover, inequality in liquid wealth exacerbates inequality in the transmission of the income shocks to expenditure. More than two-thirds of households in the bottom fifth of the income distribution have insufficient assets to maintain expenditure for even one week. Finally, we compare the relative effectiveness of the UK's CJRS and the US's EIPs. We find that the EIP would have been substantially better at helping households in the UK to maintain their usual expenditure in the short term.

Overall, this paper highlights important differences in households' abilities to cushion negative income shocks. To effectively reduce the negative and uneven consequences of COVID-19 for household welfare, it is crucial to both provide short-term liquidity (as the most affected households also have the lowest means to smooth expenditure) and, in the longer term, provide a combination of income and employment support to those with the lowest ability to work remotely and those in industries with most reduced demand. This is particularly the case as affected workers tend to be young - for these workers, losing the opportunity to accumulate human and social capitals at work could have long-term consequences for lifetime earnings. 


\title{
Supporting information
}

Additional supporting information may be found online in the Supporting Information section at the end of the article.

\author{
Appendices A-D
}

\section{References}

Adams-Prassl, A., Boneva, T., Golin, M. and Rauh, C. (2020a), 'Inequality in the impact of the coronavirus shock: evidence from real time surveys', Journal of Public Economics, 189, 104245, https://doi.org/10.1016/j.jpubeco.2020.104245.

_, - - - - and - (2020b), 'Work that can be done from home: evidence on variation within and across occupations and industries', Institute of Labor Economics (IZA), Discussion Paper 13374, https://ssrn.com/abstract=3631584.

Attanasio, O., Berloffa, G., Blundell, R. and Preston, I. (2002), 'From earnings inequality to consumption inequality', Economic Journal, 112, C52-9, https://www.jstor.org/stable/ 798358.

Benzeval, M., Burton, J., Crossley, T. F., Fisher, P., Jäckle, A., Low, H. and Read, B. (2020), 'The idiosyncratic impact of an aggregate shock: the distributional consequences of COVID-19', https://doi.org/10.2139/ssrn.3615691.

Blundell, R., Joyce, R., Costa Dias, M. and Xu, X. (2020), 'COVID-19: the impacts of the pandemic on inequality', Institute for Fiscal Studies (IFS), Briefing Note 291, https://www. ifs.org.uk/publications/14879.

-, Pistaferri, L. and Preston, I. (2008), 'Consumption inequality and partial insurance', American Economic Review, 98, 1887-921, https://doi.org/10.1257/aer.98.5.1887.

Brewer, M., Goodman, A. and Leicester, A. (2006), Household Spending in Britain: What Can It Teach Us about Poverty?, Bristol: Policy Press.

Cabinet Office (2020), 'Slides and datasets to accompany coronavirus press conference: 26 May 2020'.

Costa Dias, M., Joyce, R. and Norris Keiller, A. (2020), 'COVID-19 and the career prospects of young people', Institute for Fiscal Studies (IFS), Briefing Note 299, https://www.ifs.org. uk/publications/14914.

Cutler, D. M. and Katz, L. F. (1992), 'Rising inequality? Changes in the distribution of income and consumption in the 1980s', American Economic Review, 82, 546-51, https://www.jstor. org/stable/2117459.

Delestre, I., Joyce, R., Rasul, I. and Waters, T. (2020), 'Income protection policy during COVID19: evidence from bank account data', Institute for Fiscal Studies (IFS), Briefing Note 303, https://www.ifs.org.uk/publications/15002.

Del Rio-Chanona, R. M., Mealy, P., Pichler, A., Lafond, F. and Farmer, D. (2020), 'Supply and demand shocks in the COVID-19 pandemic: an industry and occupation perspective', COVID Economics: Vetted and Real-Time Papers, 6, 65-103.

Department for Work and Pensions (2020), 'Universal credit declarations (claims) and advances: management information'.

Dingel, J. and Neiman, B. (2020), 'How many jobs can be done at home?', COVID Economics: Vetted and Real-Time Papers, 1, 16-24.

Haldane, A. (2020), 'The Bank of England Second Quarter Speech'.

Heathcote, J., Storesletten, K. and Violante, G. L. (2014), 'Consumption and labor supply with partial insurance: an analytical framework', American Economic Review, 104, 2075-126, https://doi.org/10.1257/aer.104.7.2075. 
Hicks, M. J., Faulk, D. and Devaraj, S. (2020), 'Occupational exposure to social distancing: a preliminary analysis using O*NET data', Ball State University, Center for Business and Economic Research.

HM Revenue and Customs (2020), 'Coronavirus Job Retention Scheme official statistics'.

Joyce, R. and Xu, X. (2020), 'Sector shutdowns during the coronavirus crisis: which workers are most exposed?', Institute for Fiscal Studies (IFS), Briefing Note 278, https://www.ifs. org.uk/publications/14791.

Lekfuangfu, W. N., Piyapromdee, S., Porapakkarm, P. and Wasi, N. (2020), 'On Covid-19: new implications of job task requirements and spouse's occupational sorting', COVID Economics: Vetted and Real-Time Papers, 12, 87-103.

Mongey, S., Pilossoph, L. and Weinberg, A. (2020), 'Which workers bear the burden of social distancing policies?', COVID Economics: Vetted and Real-Time Papers, 12, 69-86.

Office for National Statistics (2020), 'Coronavirus and the economic impacts on the UK: 7 May 2020'.

Pew Charitable Trusts (2016), 'Household expenditures and income', Issue Brief, 30 March, https://www.pewtrusts.org/en/research-and-analysis/issue-briefs/2016/03/householdexpenditures-and-income.

Poterba, J. M. (1989), 'Lifetime incidence and the distributional burden of excise taxes', American Economic Review, 79, 325-30, https://www.jstor.org/stable/1827779.

Saltiel, F. (2020), 'Who can work from home in developing countries', COVID Economics: Vetted and Real-Time Papers, 6, 104-18.

US Bureau of Labor Statistics (2019), Consumer Expenditures 2018. 